\title{
IMPLEMENTASI SENSOR MONITORING PADA JARINGAN WI-FI (HOTSPOT) BERBASIS SNORT
}

\author{
Ahmad Faisol 1), Imam Izzat Muttaqin ${ }^{2)}$ \\ ${ }^{1)}$ Dosen Teknik Informatika ITN Malang \\ Jl. Raya Karanglo Km. 2 Singosari - Malang \\ ${ }^{1}$ mzfaiselecturer.itn.ac.id \\ ${ }^{2}$ Mahasiswa Teknik Elektro ITN Malang \\ Jl. Raya Karanglo Km. 2 Singosari - Malang \\ ${ }^{2}$ modunglanceng@gmail.com
}

\begin{abstract}
The wireless networking application besides giving the simplicity in communication or data exchange, also has a weakness in security system. Every user's tools that connected to the wireless network must be ready towards the appearance of the destruction or attack, because wireless network doesn't have a clear defense track. On this research, monitoring sensor application based on Snort is being suggested as one of the solutions that can be used to help the network arrangement in monitoring the condition of the network and analyze every dangerous package that is in the network. Snort will detect the intruder and analyze the package that cross the network directly and recording into the data storage media. Monitoring sensor is using rule-base system that will detect every package based on the directions that has defined to the direction data collection. The result of the research shown every new data package that entry the sensor, so the change of the event's amount of the monitoring sensor will change automatically based on the admin's arrangements. More data that cross the sensor, can influence the activity from the server that shown by the slow response from the web server.
\end{abstract}

Keywords - monitoring sensor, network security, snort, wireless networking, wlan.

\section{Pendahuluan}

Penerapan jaringan nirkabel memang memberikan banyak manfaat terutama kemudahan dalam berkomunikasi atau bertukar data. Akan tetapi, karena tidak memiliki jalur pertahanan yang jelas, model jaringan ini memiliki kerentanan dari segi keamanan. Sehingga setiap komputer yang terhubung dengan jaringan nirkabel harus selalu siap terhadap adanya gangguan atau serangan yang mungkin terjadi.

Ada beberapa metode yang sering digunakan untuk pengamanan suatu jaringan komputer. Salah satu solusi yang dapat diusulkan adalah pemasangan sensor yang dapat melakukan monitoring untuk memantau kondisi jaringan dan menganalisis setiap paket berbahaya yang dikirimkan melalui jaringan tersebut.

Berdasarkan permasalahan tersebut, penulis menggunakan Snort sebagai sensor untuk me-monitoring kondisi jaringan nirkabel, yang berfungsi untuk mendeteksi setiap paket berdasarkan aturan-aturan yang sudah didefinisikan pada kumpulan data aturan. Jika terdeteksi sebuah paket berbahaya, maka sistem akan langsung memberikan peringatan kepada kepada pengatur jaringan tentang kondisi jaringan saat itu.

Ruang lingkup pada penelitian ini adalah untuk menerapkan sensor sistem rule base yang dapat memantau kondisi keamanan 
jaringan nirkabel dengan menggunakan Snort.

\section{TinjauAn PUSTAKa}

\section{A. Jaringan Nirkabel (WLAN)}

Teknologi Wireless berarti sebuah teknologi yang tidak menggunakan kabel (nirkabel) untuk melakukan pertukaran data. Sehingga, jaringan nirkabel atau Wireless LAN (WLAN) dapat diartikan sebagai sebuah alat yang berfungsi untuk menghubungkan ke jaringan internet tanpa menggunakan kabel [1].

WLAN menggunakan dua macam teknik modulasi, yaitu Orthogonal Frequency Division Multiplexing (OFDM) dan Direct Sequence Spread Spectrum (DSSS). OFDM akan menyebabkan kecepatan pengiriman data lebih tinggi dibandingkan dengan DSSS, tetapi DSSS lebih sederhana daripada OFDM sehingga akan lebih murah dalam implementasinya. Standar yang lazim digunakan untuk WLAN adalah 802.11 yang ditetapkan oleh IEEE pada akhir tahun 1990. Standar 802.11 kemudian terbagi lagi menjadi beberapa jenis, yakni 802.11, 802.11 b, dan $802.11 \mathrm{~g}$ yang dibedakan oleh frekuensi dan kecepatannya.

\section{B. Intrusion Detection System (IDS)}

IDS adalah sebuah aplikasi perangkat lunak atau perangkat keras yang bekerja secara otomatis untuk memonitor kejadian pada jaringan komputer dan menganalisis masalah keamanan jaringan [2]. Terdapat 2 jenis IDS, yaitu :

1. Network - based IDS (NIDS)

NIDS akan melakukan pemantauan terhadap seluruh bagian pada jaringan dengan mengumpulkan paket - paket data yang terdapat pada jaringan tersebut serta melakukan analisa dan menentukan apakah paket - paket tersebut merupakan paket normal atau paket serangan.

2. Host - based IDS (HIDS)
HIDS hanya melakukan pemantauan pada perangkat komputer tertentu dalam jaringan. HIDS biasanya akan memantau kejadian seperti kesalahan login berkali kali dan melakukan pengecekan pada file.

Hal yang perlu diperhatikan pada implementasi IDS adalah perihal false positive dan false negative. False positive adalah peringatan serangan yang dihasilkan oleh IDS akan sebuah paket normal pada sistem yang dimonitor. False negative adalah sebuah serangan yang benar - benar terjadi namun terlewatkan oleh IDS sehingga IDS tidak akan menghasilkan peringatan apapun atas serangan tersebut. IDS dapat melewatkan serangan karena serangan tersebut tidak dikenali oleh IDS atau karena penyerang berhasil menggunakan sebuah metode serangan yang dapat menghindari IDS.

\section{Snort}

Snort merupakan suatu perangkat lunak untuk mendeteksi penyusup dan mampu menganalisa paket yang melintasi jaringan secara langsung dan melakukan pencatatan ke dalam penyimpanan data serta mampu mendeteksi berbagai serangan yang berasal dari luar jaringan [3]. Snort dikembangkan oleh Marty Roesch dan tersedia gratis di www.snort.org. Snort bisa digunakan pada sistem operasi linux, Windows, BSD, solaris dan sistem operasi lainnya.

Snort memanfaatkan perangkat tcpdump untuk mengambil dan menganalisis paket data terhadap sekumpulan jenis serangan yang sudah terdefinisi. Snort dapat berjalan dalam tiga mode antara lain :

- Paket sniffer, melihat paket yang lewat di jaringan.

- Paket logger, mencatat semua paket yang lewat di jaringan untuk di analisis.

- NIDS, mendeteksi serangan yang dilakukan melalui jaringan komputer dengan konfigurasi dari berbagai aturan 
yang akan membedakan sebuah paket normal dengan paket serangan.

\section{Komponen Snort}

Snort terdiri dari komponen - komponen yang mempunyai tugas dan fungsinya sendiri - sendiri yaitu [4]:

1. Packet Capture Library

Packet capture library adalah sebuah perangkat lunak yang terpisah yang mengambil paket data dari NIC. Paket paket itu adalah paket data Lapisan Data Link (OSI model) yang biasanya disebut frame yang masih belum diproses. Pada sistem Linux dan UNIX, Snort menggunakan libpcap, sedangkan pada sistem Windows, Snort menggunakan winpcap.

\section{Packet decoder}

Packet decoder mengambil frame lapisan 2 (Data Link) yang dikirimkan oleh packet capture library dan kemudian memecahnya. Pertama - tama komponen ini membaca kode sandi terhadap frame lapisan 2, kemudian paket lapisan 3 (protocol IP), lalu kemudian paket lapisan 4 (paket TCP atau UDP). Setelah proses selesai dilakukan, snort mempunyai semua informasi masing - masing protokol untuk pemrosesan lebih lanjut.

\section{Preprocessor}

Preprocessor pada Snort memiliki beberapa fitur tambahan yang dapat dimatikan atau dinyalakan. Preprocessor bekerja pada paket yang sudah dibaca kode sandinya dan kemudian melakukan transformasi pada data itu supaya lebih mudah untuk diproses oleh Snort.

\section{Detection Engine}

Komponen ini mengambil informasi dari packet decoder dan preprocessor yang kemudian memproses data itu pada lapisan Transport dan Application, membandingkan data yang terkandung dalam paket dengan aturan - aturan yang juga merupakan fitur tambahan dari komponen ini.

\section{Output}

Ketika preprocessor terpancing karena adanya data yang cocok dengan definisi jenis jaringan, Snort kemudian menghasilkan peringatan dan kemudian melakukan pencatatan. Snort mendukung beberapa macam keluaran, seperti keluaran dalam format teks atau biner. Pencatatan juga bisa dilakukan ke dalam penyimpanan data ataupun syslog.

Cara kerja sistem dari Snort untuk mengenali serangan ditunjukkan pada Gambar 1.

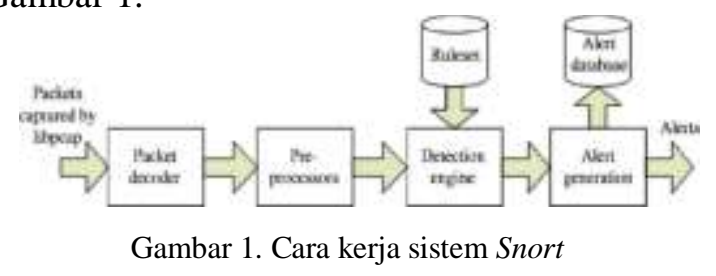

\section{Metode Penelitian}

Alur pengembangan sistem pada penelitian ini melalui beberapa tahap, antara lain:

1. Studi pendahuluan

2. Identifikasi dan perumusan masalah

3. Studi pustaka

4. Pengumpulan data (wawancara, survei lapangan, dan studi pustaka)

5. Pengolahan data (analisis kebutuhan sistem)

6. Analisis dan perancangan sistem

7. Implementasi sistem

8. Uji coba sistem

9. Kesimpulan dan saran

Pada tahap perancangan sistem, terdapat beberapa tahapan yang dilakukan, yaitu:

1. Desain sistem monitoring yang berkualitas dan handal

2. Pemilihan Software, dalam hal ini adalah pemilihan sistem operasi menggunakan Ubuntu Server 10.04 LTS 


\section{Implementasi Sensor Monitoring Pada Jaringan Wi-Fi}

3. Pemilihan sensor menggunakan Snort yang akan me-monitoring jaringan nirkabel.

Sedangkan desain sistem yang digunakan pada penelitian ini ditunjukkan pada Gambar 2.

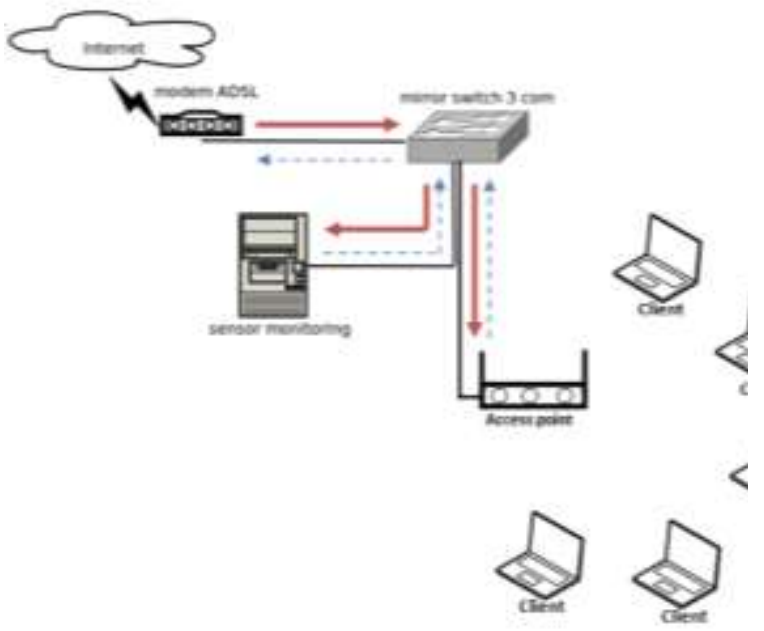

Keterangan $: \longrightarrow$ aliran data masuk $-\rightarrow$ aliran data keluar

Gambar 2. Desain Sistem Sensor Monitoring

Dari Gambar 2 tampak bahwa aliran data yang masuk dari router dikirim melalui mirror Switch kemudian paket data tersebut di copy oleh server sensor monitoring dan diteruskan ke Access Point dan disebar pada masing - masing client. Fungsi dari server sensor monitoring ini hanya meng-copy paket data yang lewat tanpa menghalangi aliran paket data yang melintas melalui mirror switch maupun Access Point.

\section{Hasil Dan Pembahasan}

Kinerja Sensor akan dipantau terus oleh pengelola atau admin dan hasilnya dari sistem sensor monitoring akan dilaporkan ke server dengan di-generate berupa $P D F$. Tujuan dari report atau pelaporan ini adalah sebagai peringatan dari sistem sensor terhadap server. Report akan dikirim ke email administrator berupa grafik jumlah total event dan real time yang dikategorikan ke dalam severity paket normal ataupun paket - paket yang mencurigakan.

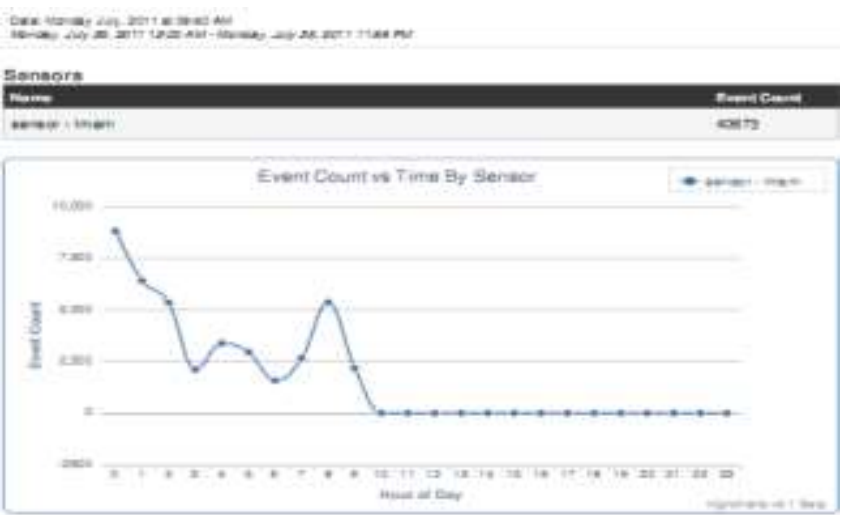

Gambar 3. Grafik Sensor Event Count

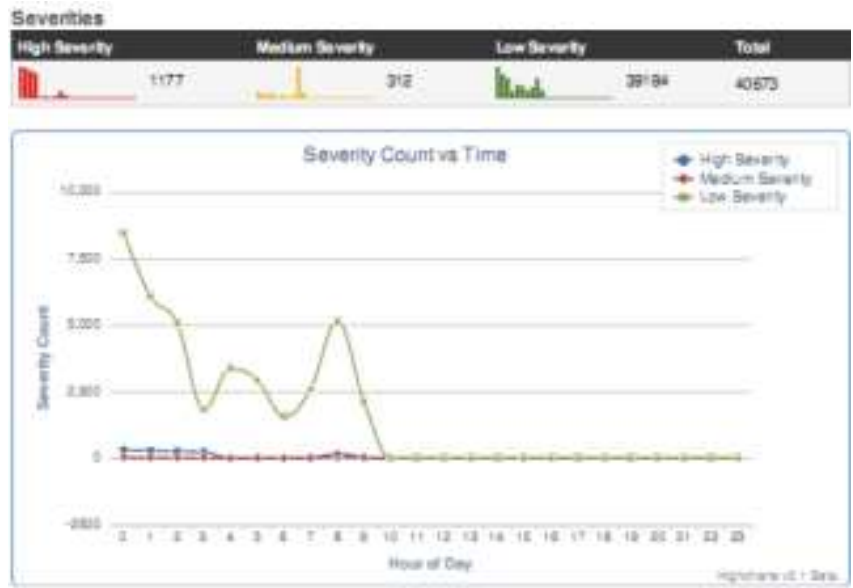

Gambar 4. Grafik Severity Event Count

Gambar 3 dan 4 menunjukkan grafik event count dan severity count per hari berdasarkan tiga kategori angka dan tampilan skala grafik (high severity, medium severity, dan low severity). Pengujian dilakukan mulai pukul 12 hingga pukul 10 dengan total mencapai 40673 severity count dan sejauh itu tingkat security event didominasi oleh paket data normal.

Tahap berikutnya adalah menampilkan laporan jumlah aktifitas berdasarkan prosentase nama event teratas dan event count yang terdaftar dalam rule base aplikasi snort, seperti ditunjukkan pada Gambar 4 yang berupa http_inspect: LONG HEADER dengan persentasi $33.18 \%$ dan jumlah event sebanyak 13424 paket data. 


\begin{tabular}{|c|c|c|}
\hline Slonaure Name & Percentige & Eve \\
\hline MP_nspect: LONG HEADEA & 33.189 & \\
\hline stream5: Reset outs de window & $29.039 \%$ & \\
\hline $\begin{array}{l}\text { IttP_ InPeC: NO CONTENT-LENGTHOR TAANSFER.ENOODING IN HTTP } \\
\text { R.. }\end{array}$ & $13.27 \%$ & \\
\hline stream5: Limt on number of overiapping TCP packets reached & $10.02 \%$ & 405 \\
\hline stream5: Bad segment, overiap ac,usted sze less than/ecual 0 & $4.41 \%$ & \\
\hline ET P2P BtTorent DHT noces reply & $2.56 \%$ & \\
\hline stream5: TCP Smal Segment Thres hold Exceeded & $228 \%$ & \\
\hline stream5: FIN number is geater than pror FIN & $1.82 \%$ & \\
\hline ET SCAN Eenavora Unusual Por 445 traftic, Paental Scan or... & $1.32 \%$ & 535 \\
\hline stream5: TCP Timestamp is misaing & $0.9 \%$ & 366 \\
\hline ET RBN Known Russ an Bus iness Nerwok (F TCP (296) & $0.26 \%$ & \\
\hline stream5: TCP whobw closed betose rece ving data & $0.2 \%$ & 80 \\
\hline ET CURRENT_EVENTS HTTP contacting a susplious ".co.cc doman & $0.15 \%$ & 62 \\
\hline ET WEB_SERVER Expot Suspected PHP ingection Artack lamd-) & $0.15 \%$ & 62 \\
\hline MtP_ Inspect: NON-RFO DEFINEDCHAR & $0.15 \%$ & 61 \\
\hline Ittp_ npect: OVERSIZE REQUEST-URI DIRECTORY & $0.1 \%$ & 39 \\
\hline smip. Attempled data hesoer butter overtion & $0.06 \%$ & 25 \\
\hline ET P2P BitTorent DHT ping request & $0.06 \%$ & 24 \\
\hline stream5: Data sent on stream not accept ing data & $0.04 \%$ & 18 \\
\hline stream5: TCP Timestamp i outs de of PAWS window & $0.04 \%$ & 15 \\
\hline
\end{tabular}

Gambar 5. Report Signature Name

Pada Gambar 6 dan 7 menunjukkan laporan jumlah 10 event teratas berdasarkan alamat IP asal terhadap tujuan. Sebagai contoh client meminta layanan internet terhadap host name berupa IP tujuan 192.168.40.5 dengan perbandingan layanan sebanyak $25.05 \%$ dan total client melakukan transaksi layanan internet sebanyak 8635 paket data.

\begin{tabular}{|c|c|c|}
\hline 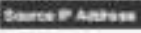 & Hascines & Eas \\
\hline lase ille es & $\pi \pi$ & 2000 \\
\hline 122.15e de? & $\tan$ & 224 \\
\hline $172=020100$ & $\tan$ & 600 \\
\hline 174,92 se 192 & $\tan$ & $5 \pi$ \\
\hline $\operatorname{san} x \cdot 13 \mathrm{zax}$ & 500 & 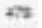 \\
\hline $19472=64$ & tres & 398 \\
\hline latrateiss & tos & $=1$ \\
\hline 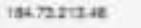 & $\operatorname{ten}$ & 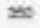 \\
\hline $17915<-488 t$ & exas & 22 \\
\hline 172106027 & 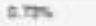 & at \\
\hline
\end{tabular}

Gambar 6. Report Source IP Address

\begin{tabular}{|c|c|c|}
\hline 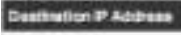 & Nusalaz & Buten caint \\
\hline 180 ved .0.5 & $2 \cos$ & 0605 \\
\hline 182 va 497 & 8.45 & 200 \\
\hline thesegeat & sest & 4007 \\
\hline ris seseat & 2ees: & sce \\
\hline $16272+3 C+84$ & 2005 & 706 \\
\hline Iakmater & tan & $\operatorname{sen}$ \\
\hline rasparat & 10 & $e$ \\
\hline nesestise & tast & st \\
\hline $1+42=312$ & tins & 50 \\
\hline Taiangeis? & $\tan$ & ses \\
\hline
\end{tabular}

Gambar 7. Report Destination IP Address

\section{KESIMPULAN}

1. Setiap aliran paket data dari router menuju mirror switch dan access point, maka sistem sensor monitoring akan bekerja pada server yaitu dengan meng-copy atau menggandakan paket data yang melalui swith $3 \mathrm{com}$.

2. Setiap paket data baru yang masuk pada sensor, maka perubahan jumlah event pada sensor monitoring akan berubah secara otomatis dan akan dilaporkan kepada administrator.

3. Semakin banyak paket data yang melewati sensor, akan berpengaruh terhadap kinerja server yang ditunjukkan dengan loading web server yang lama.

\section{DAFTAR PUSTAKa}

Wahidin. 2008. Jaringan wireless untuk orang awam. Palembang: Maxikom.

Beale, Jay. 2003. Snort 2.0 Intrusion Detection. Masachusset: Syngress Publishing, Inc.

Rafiudin, Rahmat. 2010. Mengganyang Hacker dengan SNORT. Surabaya: ANDI OFFSET.

Snort Teams. Desember 7, 2011. Snort User Manual 2.9.2. Columbia: Sourcefire, Inc.

(2001) Jogja Linux Website. [Online]. Tersedia: http://jogjalinux.or.id/berita/arsip/2010/01/14/k ustumisasi-konfigurasi-IDS-snort.

(2011) Blog Snort. [Online]. Tersedia: http://blog.snort.org/2011/02/ubuntu-1004install-guide-for-snort.html. 
Implementasi Sensor Monitoring Pada Jaringan Wi-Fi 